\title{
A First Preliminary Look: Are Corridor Charging Stations Used to Extend the Range of Electric Vehicles in the EV Project?
}

January 2013

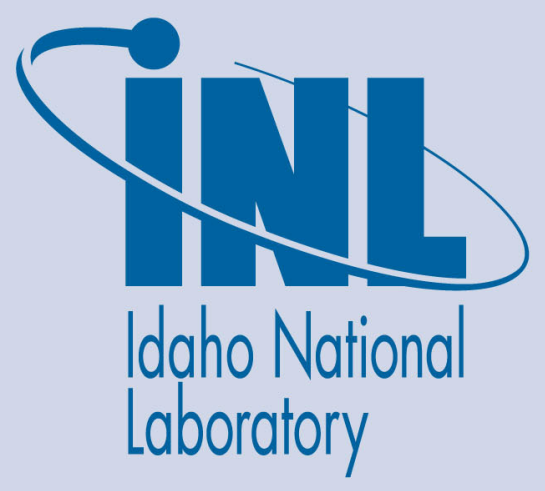

The INL is a U.S. Department of Energy National Laboratory operated by Battelle Energy Alliance 
INL/EXT-13-28269

\section{A First Preliminary Look: Are Corridor Charging Stations Used to Extend the Range of Electric Vehicles in the EV Project?}

January 2013

Idaho National Laboratory
Idaho Falls, Idaho 83415

http://www.inl.gov

Prepared for the

U.S. Department of Energy

Assistant Secretary for Energy Efficiency and Renewable Energy Under DOE Idaho Operations Office

Contract DE-AC07-05ID14517 


\section{A First Preliminary Look: Are Corridor Charging Stations Used to Extend the Range of Electric Vehicles in The EV Project?}

A preliminary analysis of data from The EV Project was performed to begin answering the question: are corridor charging stations used to extend the range of electric vehicles? Data analyzed were collected from Blink brand electric vehicle supply equipment (EVSE) units based in California, Washington, and Oregon. Analysis was performed on data logged between October 1, 2012 and January 1, 2013. It should be noted that as additional AC Level 2 EVSE and DC fast chargers are deployed, and as drivers become more familiar with the use of public charging infrastructure, future analysis may have dissimilar conclusions.

\section{Usage of EV Project EVSE on Corridors on the West Coast}

The primary focus of The EV Project is to install electric vehicle charging infrastructure in densely populated metropolitan areas. However, some charging equipment has been installed along travel corridors between cities. In California, Washington, and Oregon, 12 EV Project Blink EVSE have been installed at four distinct locations along corridors. For the purpose of this report, a corridor EVSE is defined as one located within 2 miles of a state or interstate highway and outside the limits of major cities. Two of the four corridor EVSE locations are adjacent to restaurants and retail outlets with immediate access to Interstate5 . The other two charging sites are at restaurants on state highways. All 12 charging units are accessible for charging by the general public. 10 units are AC Level 2 EVSE. Two are DC fast chargers.

In the fourth quarter of 2012, 55 distinct vehicle owners performed 92 charging events collectively on the 10, Level 2 corridor EVSE. The four charging sites experienced 0.27 Level 2 charging events per site per day, or 1.9 Level 2 charging events per site per week, on average. The 10 Level 2 EVSE were connected to vehicles for an average of 1.26 hours per charging event and 0.34 hours per site per day. They consumed $380 \mathrm{kWh}$ while charging vehicles, which equates to $4.1 \mathrm{kWh}$ per charge.

The DC fast chargers were used by 64 distinct vehicle owners, who performed 151 charging events in the reporting quarter. The DC fast chargers experienced 1.0 charging events per unit per day. Vehicles were connected to the DC fast chargers for an average of 19 minutes per charge. They consumed 1,190 kWh

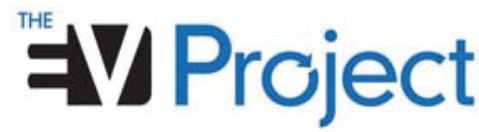

while charging vehicles, or $7.9 \mathrm{kWh}$ per charge. The fast charger located on I-5 experienced over two times the number of charging events and over three times the connected time and energy consumption as the other fast charger located on a state highway. At both fast charger sites, Level 2 EVSE are located along side the DC fast chargers. The DC fast chargers were clearly favored at both of these sites, as shown in Figure 1. Fast charging was chosen 2.5 times as often as Level 2 charging and was responsible for over 5 times the energy consumption at $3 / 4$ of the time connected. (It should be noted that some vehicles that chose to charge using Level 2 units at these locations may not be capable of fast charging.)

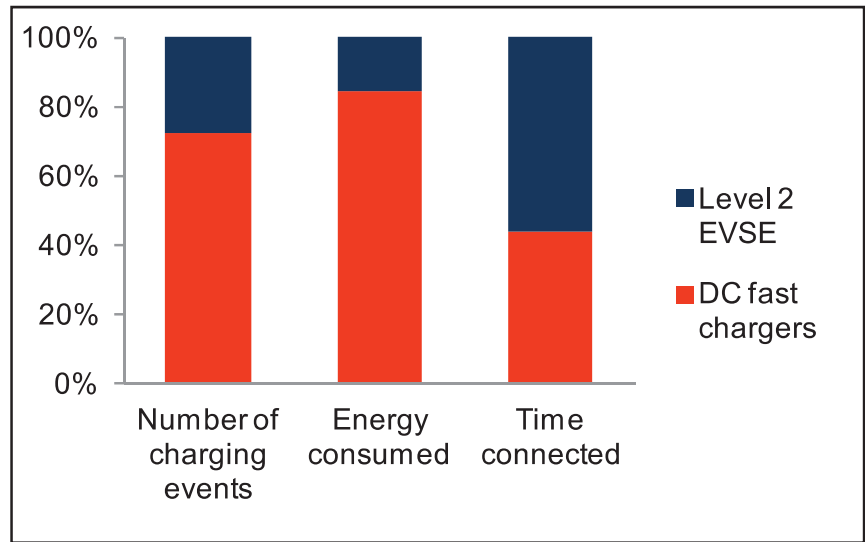

Figure 1: Usage of Level 2 EVSE versus DC fast chargers at two corridor charging locations.

\section{Vehicle Distance from Home When Using Corridor EVSE}

During Q4 2012, EV Project Nissan LEAFs and other vehicles connected to the 12 corridor EVSE at locations ranging from 8 to 190 miles from their homes (measured as straight-line distance, or "as the crow flies"). Figure 2 shows the distribution of distance from home. It is clear that the charging event by a vehicle 190 miles from home is an extreme outlier. All other charging events were conducted by vehicles within 50 miles of home. 


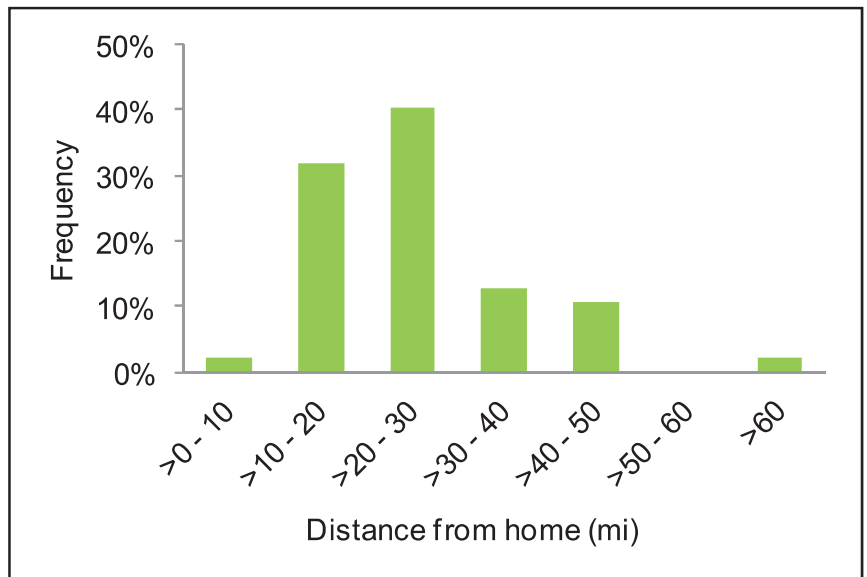

\section{$\exists \boldsymbol{V} /$ Project}

Figure 2: Distribution of vehicle distance from home when charging at corridor EVSE.

\section{Conclusion}

Preliminary analysis showed that in the last quarter of 2012, EVSE at four locations along travel corridors received low usage. DC fast chargers were favored over Level 2 EVSE. Also, charging units located by a major interstate were used more than EVSE on state highways. Electric vehicles that charged at the four locations studied were located from 8 to 190 miles away from home when charging. In at least one case, the corridor EVSE facilitated travel beyond the range of the electric vehicle's battery. Nearly $75 \%$ of vehicles were between 8 and 30 miles from home, suggesting that most vehicle owners using corridor EVSE were not concerned with significant range extension. However, more sophisticated analysis of vehicle driving before and after charging and analysis of a larger sample of corridor EVSE and vehicles are warranted before drawing generalized conclusions.

\section{About The EV Project}

The EV Project is the largest electric vehicle infrastructure demonstration project in the world; designed and managed by ECOtality North America, with a budget of over $\$ 230$ million USD, equally funded by the U.S. Department of Energy through the American Recovery and Reinvestment Act and ECOtality North America. The EV Project will deploy and study approximately 13,000 Level 2 EVSE charging stations for residential and commercial use, as well as 400 DC Fast Charge ports, in conjunction with the usage data from 8,000 Nissan LEAFTM, Chevrolet Volts and Smart ForTwo Electric Drives. This project will collect, analyze data, and publish lessons learned on vehicles, EVSE, and driver behavior. This material is based upon work supported by the Department of Energy under Award Number DE-E0002194.

For more information, visit www.theevproject.com or contact ECOtality at 602-716-9576. 